\title{
REVIEW
}

\section{Telomeres and atherosclerosis}

\author{
L. Carulli ${ }^{\text {a,* }}$, E. Annicchiarico ${ }^{\text {b }}$ \\ ${ }^{a}$ Department of Biomedical, Metabolic and Neural Sciences, University of Modena and Reggio Emilia, Modena, Italy \\ ${ }^{b}$ Department of Intensive Care, Cardiology Unit, Nuovo Ospedale Civile Sant'Agostino Estense, Modena, Italy \\ Received 5 May 2014; received in revised form 30 June 2014; accepted 8 July 2014 \\ Available online
}

\section{KEYWORDS \\ Telomere; \\ Telomerase; \\ Leukocyte telomere \\ length; \\ Coronary arteries \\ disease; \\ Oxidative stress; \\ Inflammation; \\ Endothelial cells; \\ Hematopoietic stem \\ cells}

\begin{abstract}
The pathogenesis of atherosclerosis, an age-related disorder, may be due to a premature biological ageing. Cellular senescence, the finite replicative lifespan of cells, plays a critical role in the pathogenesis of atherosclerosis. The biological mechanism that triggers the onset of cellular senescence is thought to be telomere shortening. The two major mechanisms responsible for telomere shortening are the end-replication problem, oxidative DNA damage as well as inflammation induced by environmental risk factors. Repair of the endothelium depends on the presence of endothelial progenitor cells which depends on the hematopoietic stem cells (HSC) reserves. In numerous past studies, short LTL has been associated with atherosclerosis. Here we review the literature on telomere biology and coronary artery disease (CAD).

(c) 2014 Elsevier B.V. All rights reserved.
\end{abstract}

\section{Introduction}

Atherosclerosis, an age-related disorder [1] may recognize as a determinant factor a premature biological ageing. In fact cellular senescence, defined as the finite replicative lifespan of cells, plays a critical role in its pathogenesis [2-4]. An important feature of atherosclerosis is vascular endothelial cell dysfunction. Studies on atherosclerotic plaques have demonstrated that endothelial and vascular smooth muscle cells in atherosclerotic lesions display changes of senescence $[5,6]$. In stable atherosclerotic

\footnotetext{
Abbreviations: HSC, hematopoietic stem cells; CAD, coronary arteries disease; LTL, leukocyte telomere length,; MI, myocardial infarction; T2D, type 2 diabetes.

* Corresponding author. Department of Biomedical, Metabolic and Neural Sciences. University of Modena and Reggio Emilia, Via Giardini 1355, 41126 Modena, Italy. Tel.: +39 059 3961804; fax: +39059 3961335.

E-mail addresses: lucia.carulli@unimore.it, carullilucia@hotmail.com (L. Carulli).
}

plaques there are few senescent cells, whereas in advanced, complicated plaques, senescent cells accumulate because of high cell turnover [7]. The biological mechanism that triggers the onset of cellular senescence is thought to be telomere shortening. Telomeres are structures composed of DNA repeats that protect the end of chromosomes, but shorten at each cell division. Recently their role in the onset, development and prognosis of cardiovascular disease has generated considerable interest leading to a number of studies investigating telomeres length and cardiovascular disease. In this regard telomere shortening has been reported to be associated also with the classical risk factors for atherosclerosis such as insulin resistance [8,9] diabetes [10-13], obesity [14], hypertension $[8]$ and smoking $[14,15]$.

Overall this would suggest that cellular senescence may represent the ultimate event responsible for the pathological changes characteristic of atherosclerosis. Such a view would theoretically have several implications. Firstly understanding the relation between telomere biology and 
cardiovascular disease may help elucidate ways to measure cardiovascular aging based not only on physiological changes but also by the use of biomarkers such as leukocyte telomere length (LTL). Secondly, it may help to better define the need and the type of interventions on the risk factors for atherosclerosis. Thirdly the understanding of cardiovascular aging and telomere biology may help to identify new strategies of interventions such as stem cell therapy or agents that could retard this aging process beyond conventional risk factors.

\section{The telomere complex}

Telomeres consist of repetitive DNA sequences (TTAGGG) associated with a specialized protein complex named shelterin and are located at the ends of linear chromosomes. They function as a cap to stabilize and protect chromosomes from erosion and from being mistaken for double-strand DNA breaks [16]. During each cell division, telomeres shorten due to the "end-replication problem" that is the DNA polymerase's inability to fully replicate the $3^{\prime}$ end of chromosomes. In order to limit telomere attrition, germline and some somatic cells express telomerase, a reverse transcriptase that maintains telomere length by synthesizing new DNA sequences and adding them to the end of the chromosome [17]. Telomerase is an enzymatic protein complex including the telomerase reverse transcriptase (TERT) and the telomerase RNA component (TERC) used as a template to synthesize telomere DNA. When telomeres are too short, they signal the arrest of cell proliferation resulting in cell senescence or apoptosis. If protective mechanisms, such as the p53 tumor-suppressor gene, are inactive, thus allowing continued proliferation, telomeres become extremely short and dysfunctional; they may cause chromosomes end-to-end fusions and ultimately chromosomal instability. Conversely, cells transfected with the telomerase gene can proliferate indefinitely [18]. Despite telomerase activity, telomere shortening is inevitable, thereby limiting the proliferative lifespan of human cells. As expected, for a given organ, telomere length decreases with the age of the subjects. There are also iatrogenic causes of telomere shortening: for example after bone marrow transplantation when hematopoietic stem cells and progenitor cells are highly proliferative in order to reconstitute hematopoiesis. In addition, telomere attrition may be genetically determined as a result of telomerase complex's genes mutations leading to an inherited inability to elongate telomeres [19]. Variability in telomere length is influenced by heredity, race and gender. It is known that telomere length is shorter in healthy offspring of patients with coronary artery disease (CAD) $[20,21]$. This finding offers some explanation for the increased familial risk of CAD and also implies that shorter telomeres are likely a primary abnormality in the pathogenesis of the disease [22]. It is also known AfricanAmericans have longer telomeres than Caucasians and Indians [23-25] and females have longer telomeres than their males counterparts [26].

\section{Telomere and endothelial cells}

The atherosclerotic process is characterized by endothelial cell dysfunction therefore is dependent on the balance between injury and repair of the endothelium-injury from oxidative stress and inflammation, and repair by hematopoietic stem cell reserves (HSC).

An important mechanism responsible for telomere shortening is the oxidative DNA damage induced by environmental risk factors (Fig. 1). Telomere shortening induced by oxidative stress is proportional to telomere length, as longer telomeres are larger targets for free radicals $[27,28]$. Telomeres are exposed to reactive oxygen species, which have a predilection for the single stranded, $\mathrm{G}$-rich telomere overhang. This site specificity for guanine is because guanine is the most easily oxidized DNA base as its oxidation potential is lower compared to the other three bases. This is an important variable associated with aging and with accelerating the telomere attrition [29]. An important consequence of oxidative stress is the initiation of an inflammatory response (Fig. 1). Chronic systemic inflammation is responsible for an increase in peripheral white blood cell turnover, which in turn leads to an exaggerated telomere attrition rate [30]. The increased white cell consumption induces hematopoietic stem cells to divide, thereby shortening their telomere length as well. Moreover exposure to TNF- $\alpha$ also reduces telomere length by negative regulation of telomerase activity [31]. In several studies it has been shown that short telomeres are associated with the classical risk factor for atherosclerosis: hypertension [8] diabetes [32,33], coronary artery disease, carotid atherosclerosis [34,35] and stroke [14,36,37]. This could be due to chronic inflammation that associates with these clinical conditions and/or to the influence of a less healthy life style, including smoking habit and alcohol consumption [14].

Repair of the endothelium depends on the presence of endothelial progenitor cells on the sites of vascular injury to initiate repair. Endothelial progenitor cells are produced by HSC, which, due to their higher telomerase activity, have a greater proliferative capacity. Exhaustion of the progenitor cell is an important factor in endothelial cell dysfunction and shortened telomere length in HSC is indicative of diminished reparative capacity $[22,23]$.

Telomere length quantification is generally determined on DNA sourced from circulating white blood cells. The problem is whether telomere length determination in peripheral blood cells really reflects the tissue cell telomere length. Some studies have shown that the correlation between LTL and telomere length in vascular tissue really exists. The study by Wilson et al. demonstrated that telomere attrition in circulating blood leucocytes reflects similar changes in the vasculature and is an acceptable surrogate for vascular ageing in population studies [37]. In concordance with this, there is evidence that the relation between LTL and telomere length in various human tissues is strong [38]. In another study LTL was related to the presence of carotid atherosclerotic plaque but not with the plaque telomere length; plaque telomere length was 


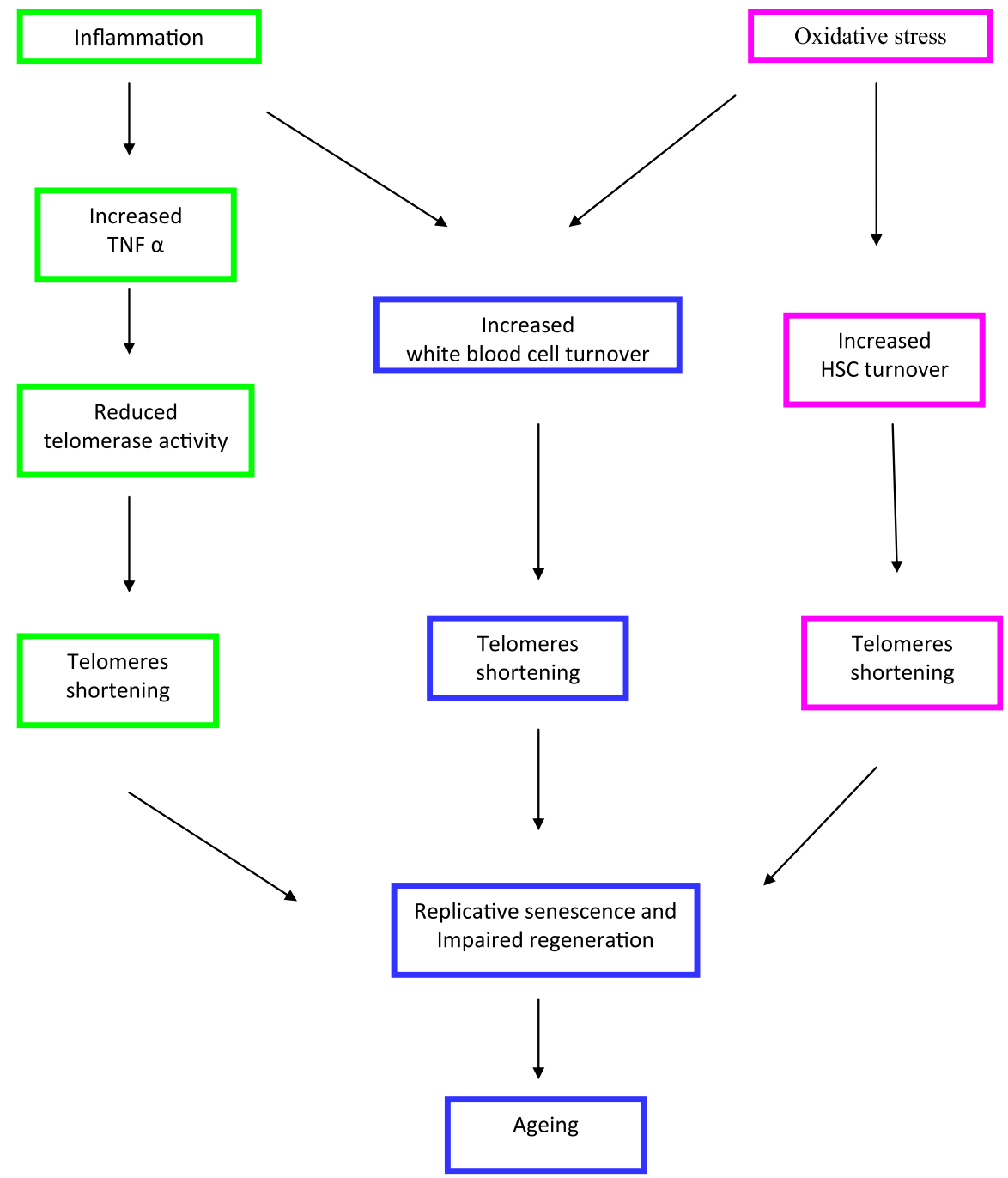

Figure 1 Telomere shortening induced by inflammation and oxidative stress. Systemic inflammation through an increase in peripheral white blood cell turnover and increased TNF- $\alpha$ also plasma levels, that reduces telomerase activity, leads to telomeres attrition as well as does oxidative stress increasing HSC turnover.

related to the plaque characteristics and development of restenosis after endarterectomy in a group of patients undergoing angiography and intervention [39].

\section{Telomeres and classical atherosclerosis risk factors}

It has been recently stressed the association of short telomeres with the classical risk factor for atherosclerosis (Fig. 2).

\section{Insulin resistance and diabetes}

The pro-atherogenic mechanism of insulin resistance includes its systemic effects leading to dyslipidaemia, hypertension and a pro-inflammatory state as well as direct effects on vascular endothelial cells, smooth muscle cells and macrophages [40].

In early atherosclerosis, insulin resistance causes decreased nitric oxide production and an increase in
VCAM-1, which are responsible for impaired vasodilation and inflammation.

In advanced plaques, insulin resistance triggers apoptosis of cells via the Akt pathway [41-44].

Apoptosis of smooth muscle cells causing fibrous cap thinning and apoptosis of macrophages leading to plaque necrosis are the pathological processes that precipitate acute coronary syndromes.

In type 2 diabetes, hyperglycaemia "per se", induces oxidative stress [45-48] and ultimately leads to cellular senescence. Cellular senescence and apoptosis occur not only in vascular endothelial and smooth muscle cells but in multiple cell lines, including endothelial progenitor $[49,50]$.

Therefore type 2 diabetes can be considered a premature-ageing syndrome and several clinical studies have shown an association between shorter telomere length and type 2 diabetes (T2D) [10-13]. The extent of telomere shortening seems to be gradual and reflecting the severity of the disease and the presence of complications [51]. 


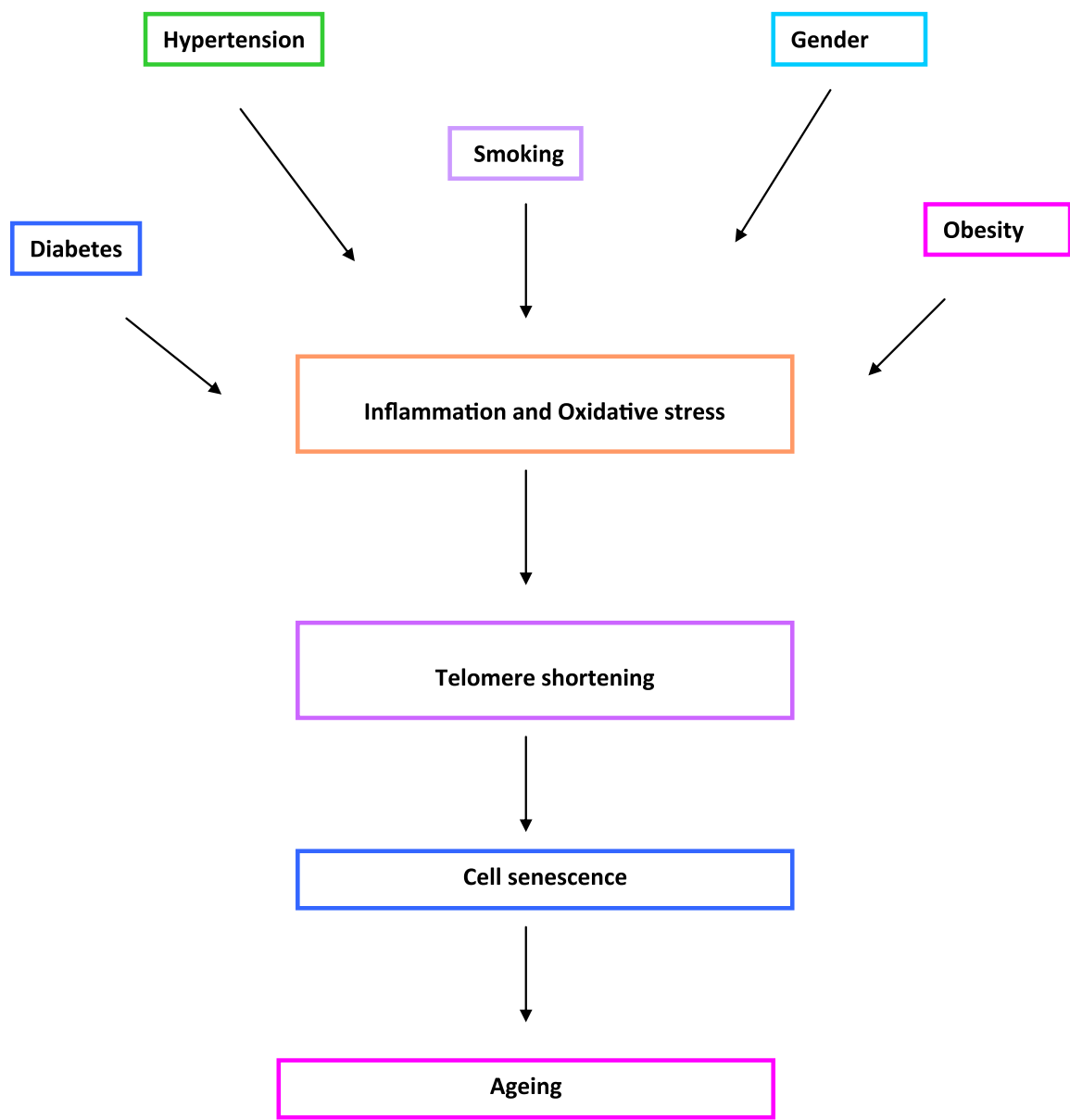

Figure 2 Telomeres and classical atherosclerosis risk factors. The association between short telomeres and the classical risk factors for atherosclerosis might be mediated by systemic inflammation and oxidative stress and/or the influence of a less healthy life style (smoking habit, alcohol consumption, physical inactivity) that usually associates with these conditions.

Also the metabolic syndrome seems to have an influence on telomere length, in a study by Satoh et al. it has been shown that CAD patients with the metabolic syndrome had shorter telomeres than CAD patients without the metabolic syndrome [52]. Moreover among diabetic patients, those with atherosclerotic plaques have greater shortening of telomere length compared to those without plaques [53].

Finally diabetic patients with myocardial infarction have shorter telomeres than diabetic subjects without myocardial infarction $[13,54]$.

Based on these observations, it has been postulated that critically shortened telomeres, due to a combination of inherited short telomeres, oxidative stress and inflammation induced telomere attrition, caused by the common risk factors, lead to cellular ageing in vascular endothelial, and may be a useful biomarker of tissue ageing and disease progression.

\section{Obesity}

Adipose tissue is not only a source of ROS and proinflammatory cytokines but also secretes of bioactive peptides named "adipokines" that impact on multiple functions including insulin sensitivity, angiogenesis and blood pressure, lipid metabolism and hemostasis, all of which influence the function and structural integrity of the cardiovascular system $[55,56]$.

Indeed obesity promotes the clustering of risk factors such as dyslipidaemia, hypertension, diabetes and the metabolic syndrome and obese subjects experience elevated morbidity and mortality from all forms of cardiovascular disease [57,58].

It is interesting to point out that the relation between weight gain (BMI) and telomere shortening rate is accounted for by increased insulin resistance rather than body weight per se.

In the Bogalusa Heart study it was observed that the relative changes in telomere length were correlated with the homeostasis model assessment of insulin resistance and changes in the body mass index [9].

In a study conducted on 1122 healthy adult female twins it was observed that the telomere length in obese women were 240 base pairs shorter compared to the lean sibling and the difference in telomere length accounted for 8.8 years of ageing.

The study also suggested that the mechanism by which obesity affects telomere length is through increased leptin levels rather than BMI per se $[14,59]$. 


\section{Hypertension}

Systolic blood pressure rises with age and might be considered as a phenotype of biological ageing. In a study conducted on 49 twin pairs from the Danish Twin Register, it was observed a significant inverse correlation between pulse pressure and telomere length [60] and this correlation was highly familial.

In a study on 163 treated hypertensive males, Benetos et al. observed that telomere length was shorter in hypertensive men with carotid plaques compared to hypertensive men without plaque. The findings from this study suggest that in the presence of hypertension, which is a major risk factor for carotid arteries atherosclerosis, short telomere act as an important additional risk factor [61].

\section{Smoking}

Smoking appears to result in an elevation of biomarkers od oxidant stress, some in a dose-related fashion. There is also evidence that endothelial dysfunction in smokers may be attributable to oxidative stress [62].

Several epidemiological studies, have shown an association between telomere shortening and smoking habit.

In the Flemish study on environment, genes and health outcomes, shorter telomeres were observed in smokers compared to non-smokers [26]. In another study women who had never smoked had longer telomeres than former smokers, and both had longer telomeres than current smokers, moreover it was observed that the effect of smoking habit on telomere length was dose-dependent; each pack-year smoked was equivalent to the loss of an additional five base pairs (18\%) of telomere length compared to the rate in the overall cohort [14].

The dose dependent effect was subsequently replicated in another study conducted on a cohort of male smokers with and without chronic obstructive pulmonary disease; the study confirmed that the smoking exposure enhances telomere shortening and demonstrated a dose effect relationship independently from the presence chronic pulmonary obstruction [15].

\section{Telomere length and atherosclerosis}

It has been shown that in atherosclerotic regions of coronary arteries, endothelial cells present characteristic features of senescence and inhibiting telomere function induced senescence, whereas introducing telomerase suppressed senescence and extended the lifespan of endothelial cells [3]. It is known that telomeres of coronary endothelial cells are shorter in patients with CAD compared to age-matched subjects without CAD and that in the CAD patients, telomere length is shorter in endothelial cells at atherosclerotic sites compared to nonatherosclerotic sites [63]. Studies have also shown that endothelial cells in regions of the vascular tree that are subjected to greater hemodynamic stress have more pronounced telomere attrition than endothelial cells from areas with less stress [64], this is because that areas of the vasculature that undergo greater shear wall stress have higher cellular turnover rates and consequently shorter telomere length [65]. This variable telomere attrition rate indicates the significant impact of environmental stress on telomere length. In numerous past studies, short LTL has been associated with CAD $[23,34,66]$. In the pioneering study by Samani et al., it was observed that in patients with early onset CAD with premature myocardial infarction (MI) had a shorter mean telomere length compared with age and gender matched healthy subjects. Furthermore, although both groups experienced telomere attrition with aging, there was a residual difference that served as a marker of increased cardiovascular risk in those patients with early CAD [67]. In another study patients with premature MI had significantly shorter mean telomere lengths compared to healthy subjects, with a consequent calculated reduction in biological age of 11.3 years [68]; the same results were observed in a study that associated shorter LTL with an increase in prospective risk of MI [69]. A study on 143 normal blood donors over the age of 60 years, showed that subjects with shorter telomeres had poorer survival, with a 3.18-fold higher mortality rate from heart disease [70]. In a sub-study of the West of Scotland Primary Prevention Study (WOSCOPS) comparing telomere lengths at recruitment in individuals who went on to develop coronary heart disease events with those from age-matched controls who remained free of CAD, it was shown that subjects with shorter telomere length at the time of recruitment had a significantly higher risk of developing subsequent coronary heart disease [71]. It has been also observed that LTL is shorter in patients with carotid plaques compared with those without, however, further studies are needed to compare peripheral measurements with those in central tissue to determine whether there is a close correlation between measurements as indicated previously [31]. Finally, in the prospective population-based Bruneck study, baseline telomere length was a significant risk predictor for subsequent myocardial infarction and stroke, independent of standard risk factors. Of note in this study telomere length was strongly associated with advanced pathology and acute vascular syndromes but not early atherosclerosis [7].

\section{Conclusion}

Understanding the relation between telomere biology and atherosclerosis may be important because of the high incidence of both premature $\mathrm{CAD}$ in the general population.

Short telomere in the early life may indicate a genetic predisposition and therefore help identifying susceptible individuals who may be appropriate targets for future molecular therapies and candidates for educational and surveillance programs.

In addition, in adult life telomere length might be a measure of cumulative DNA damage from multiple environmental risk factors, therefore it might be a better predictor of CAD than the currently available risk markers, which are single, point measurements in time. 
Studies with a large number of patients affected by short telomere are needed to evaluate the real rate of association of clinical or subclinical CAD and the prevalence of telomeres shortening. Finally, novel therapies aimed at delaying cellular senescence by manipulation of the telomere/telomerase complex may be of benefit.

\section{Conflict of interest}

\section{Authors declare no conflict of interest.}

\section{References}

[1] Lusis AJ. Atheroscler Nat 2000;407:233-41.

[2] Minamino T, Komuro I. Vascular cell senescence: contribution to atherosclerosis. Circ Res 2007;100:15-26.

[3] Minamino T, Miyauchi $\mathrm{H}$, Yoshida $\mathrm{T}$, Ishida $\mathrm{Y}$, Yoshida $\mathrm{H}$, Komuro I. Endothelial cell senescence in human atherosclerosis: role of telomere in endothelial dysfunction. Circulation 2002: $105: 1541-4$

[4] Serrano AL, Andres V. Telomeres and cardiovascular disease does size matter? Circ Res 2004;94:575-84.

[5] Burrig KF. The endothelium of advanced atherosclerotic plaques in humans. Arterioscler Thromb 1991:11:1678-89.

[6] Ross R, Wight TN, Strandness E, Thiele B. Human atherosclerosis. Cell constitution and characteristics of advanced lesions of the superficial femoral artery. Am J Pathol 1984;114:79-93.

[7] Willeit P, Willeit J, Brandstatter A, Ehrlenbach S, Mayr A, Gasperi A, et al. Cellular aging reflected by leukocyte telomere length predicts advanced atherosclerosis and cardiovascular disease risk. Arterioscler Thromb Vasc Biol 2010;30:1649-56.

[8] Demissie S, Levy D, Benjamin EJ, Cupples LA, Gardner JP, Herbert A, et al. Insulin resistance, oxidative stress, hypertension, and leukocyte telomere length in men from the Framingham heart study. Aging Cell 2006;5:325-30.

[9] Gardner JP, Shengxu L, Srinivasan SR, Wei C, Kimura M, Lu X, et al. Rise in insulin resistance is associated with escalated telomere attrition. Circulation 2005;111:2171-7.

[10] Adaikalakoteswari A, Balasubramanyam M, Mohan V. Telomere shortening occurs in Asian Indian type 2 diabetic patients. Diabet Med 2005;22:1151-6.

[11] Sampson MJ, Winterbone MS, Hughes JC, Dozio N, Hughes DA Monocyte telomere shortening and oxidative DNA damage in type 2 diabetes. Diabetes Care 2006;29:283-9.

[12] Zee RL, Castonguay AJ, Barton NS, Germer S, Martin M. Mean leucocyte telomere length shortening and type 2 diabetes mellitus: a case-control study. Transl Res 2010;155:166-9.

[13] Salpea KD, Talmud PJ, Cooper JA, Maubaret CG, Stephens JW, Abelak K, et al. Association of telomere length with type 2 diabetes, oxidative and UCP2 gene variation. Atherosclerosis 2010 Mar;209(1):42-50.

[14] Valdes AM, Andrew T, Gardner JP, Kimura M, Oelsner E, Cherkas LF, et al. Obesity, cigarette smoking, and telomere length in women. Lancet 2005;366:662-4.

[15] Morla M, Busquets X, Pons J, Sauleda J, MacNee W, Agusti AGN. Telomere shortening in smokers with and without COPD. Eur Respir J 2006;27:525-8.

[16] Blackburn EH. Switching and signaling at the telomere. Cell 2001;106:661-73.

[17] Greider CW, Blackburn EH. Identification of a specific telomere terminal transferase activity in tetrahymena extracts. Cell 1985; 43:405-13.

[18] Hahn WC, Counter CM, Lundberg AS, Beijersbergen RL, Brooks MW, Weinberg RA. Creation of human tumour cells with defined genetic elements. Nature 1999;400:464-8. http: //dx.doi.org/10.1038/22780. PMID:10440377.

[19] Carulli L, Dei Cas A, Nascimbeni F. Synchronous cryptogenic liver cirrhosis and idiopathic pulmonary fibrosis: a clue to telomeres involvement on line publication. Hepatology 2012;56(5):2001-3.

[20] Brouilette SW, Whittaker A, Stevens SE, van der Harst P, Goodall AH, Samani NJ, et al. Telomere length is shorter in healthy offspring of subjects with coronary artery disease: support for the telomere hypothesis. Heart 2008;94:422-5.

[21] Dei Cas A, Spigoni V, Franzini L, Preti M, Ardigò D, Derlindati E, et al. Lower endothelial progenitor cell number, family history of cardiovascular disease and reduced HDL-cholesterol levels are associated with shorter leukocyte telomere length in healthy young adults. Nutr Metab Cardiovasc Dis. doi.org/10.1016/j.numecd.2011.04.005.

[22] Aviv A. Genetics of leukocyte telomere length and its role in atherosclerosis. Mutat Res Fundam Mol Mech Mutagen 2012; 730:68-74.

[23] De Meyer T, Rietzschel ER, de Buyzere ML, van Criekinge W, Bekaert S. Telomere length and cardiovascular ageing: the means to the ends? Ageing Res Rev 2011;10(2):297-303.

[24] Hunt SC, Chen W, Gardner JP, Kimura M, Srinivasan SR, Eckfeldt $\mathrm{JH}$, et al. Leukocyte telomeres are longer in African Americans than whites: the National heart, lung, and blood institute family heart study and the Bogalusa heart study. Aging Cell 2008;7:451-8.

[25] Zhu H, Wang X, Gutin B, Davis CL, Keeton D, Thomas J, et al. Leukocyte telomere length in healthy Caucasian and AfricanAmerican adolescents: relationships with race, sex, adiposity, adipokines and physical activity. J Pediatr 2011;158:215-20.

[26] Nawrot TS, Staessen JA, Gardner JP, Aviv A. Telomere length and possible link to X chromosome. Lancet 2004:363:507-10.

[27] Von Zglinicki T. Oxidative stress shortens telomeres. Trends Biochem Sci 2002;27:339-44.

[28] De Meyer T, Rietzschel ER, De Buyzere ML, Langlois MR, De Bacquer D, Segers P, et al. Systemic telomere length and preclinical atherosclerosis: the Asklepios study. Eur Heart J 2009:30:3074-81.

[29] Naka K, Muraguchi T, Hoshii T, Hirao A. Regulation of reactive oxygen species and genomic stability in hematopoietic stem cells. Antioxid Redox Signal 2008;10:1883-94.

[30] Floyd RA, Hensley K, Jaffery F, Maidt L, Robinson K, Pye Q, et al. Increased oxidative stress brought on by pro-inflammatory cytokines in neuro-degenerative processes and the protective role of nitrone-based free radical traps. Life Sci 1999;65:1893-9.

[31] Beyne-Rauzy O, Prade-Houdellier N, Demur C, Recher C, Aye J, Laurent $G$, et al. Tumour necrosis factor alpha inhibits h-TERT gene expression in human myeloid normal and leukemic cells. Blood 2005;106:3200-5.

[32] Astrup AS, Tarnow L, Jorsal A, Lajer M, Nzietchueng R, Benetos A, et al. Telomere length predicts all cause mortality in patients with type 1 diabetes. Diabetologia 2010;53:45-8.

[33] Murillo-Ortiz B, Albarr an-Tamayo F, Arenas-Aranda D, BenítezBribiesca L, Malacara-Hernández JM, Martínez-Garza S, et al. Telomere length and type 2 diabetes in males: a premature aging syndrome. Aging Male 2012;15:54-8.

[34] Fyhrquist F, Saijonmaa O, Strandberg T. The roles of senescence and telomere shortening in cardiovascular disease. Nat Rev Cardiol 2013;10(5):274-83.

[35] O'Donnell CJ, Demissie S, Kimura M, et al. Leukocyte telomere length and carotid artery intimal medial thickness: the Framingham heart study. Arterioscler Thromb Vasc Biol 2008;28: 1165-71.

[36] Ding H, Chen C, Shaffer JR, Liu L, Xu Y, Wang X, et al. Telomere length and risk of stroke in Chinese. Stroke 2012;43:658-63.

[37] Wilson WR, Herbert KE, Mistry Y, Stevens SE, Patel HR, Hastings RA, et al. Blood leucocyte telomere DNA content predicts vascular telomere DNA content in humans with and without vascular disease. Eur Heart J 2008;29:2689-94.

[38] Butler MG, Tilburt J, Devires S, Muralidhar B, Aue G, Hedges L, et al. Comparison of chromosomes telomere integrity in multiple tissue from subjects at different ages. Cancer Genet Cytogent 1998;105:138-44.

[39] Huzen J, Peeters W, de Boer RA, Moll FL, Wong LS, Codd V, et al. Circulating leukocyte and carotid atherosclerotic plaque telomere length: interrelation, association with plaque characteristics, and restenosis after endarterectomy. Arterioscler Thromb Vasc Biol 2011 May;31(5):1219-25.

[40] De Fronzo RA. Insulin resistance, lipotoxicity, type 2 diabetes and atherosclerosis: the missing links. The Claude Bernard lecture 2009. Diabetologia 2009;53:1270-87.

[41] Bornfeldt KE, Tabas I. Insulin resistance, hyperglycaemia and atherosclerosis. Cell Metab 2011;14:575-85. 
[42] Kido Y, Nakae J, Accili D. Clinical review 125: the insulin receptor and its cellular targets. J Clin Endocrinol Metab 2001;86:972-9.

[43] Miyauchi H, Minamino T, Tateno K, Kunieda T, Toko H, Komuro I. Akt negatively regulates the in-vitro lifespan of human endothelial cells via a p53/p21-dependent pathway. EMBO J 2004;23: 212-20.

[44] Cantley LC. The phosphoinositide 3-kinase pathway. Science 2002;296:1655-7.

[45] Esposito K, Nappo F, Marfella R, Giugliano G, Giugliano F, Ciotola $\mathrm{M}$, et al. Inflammatory cytokine concentrations are acutely increased by hyperglycaemia in humans: role of oxidative stress. Circulation 2002:106:2067-72.

[46] Su Y, Liu XM, Sun YM, Jin HB, Fu R, Wang YY, et al. The relationship between endothelial dysfunction and oxidative stress in diabetes and pre-diabetes. Int J Clin Pract 2008;62:877-82.

[47] Hansel B, Giral P, Nobecourt E, Chantepie S, Bruckert E, Chapman MJ, et al. Metabolic syndrome is associated with elevated oxidative stress and dysfunctional dense HDL particles displaying impaired anti-oxidative activity. J Clin Endocrinol Metab 2004;89:4963-71.

[48] Nishikawa T, Edelstein D, Du XL, Yamagishi S, Matsumura T, Kaneda Y, et al. Normalizing mitochondrial super-oxide production blocks 3 pathways of hyperglycaemic damage. Nature 2000;404:787-90.

[49] Brodsky SV, Gealekman O, Chen J, Zhang F, Togashi N, Crabtree M, et al. Prevention and reversal of premature endothelial cell senescence and vasculopathy in obesity-induced diabetes by ebselen. Circ Res 2004;94:377-84.

[50] Rosso A, Balsamo A, Gambino R, Dentelli P, Falcioni R, Cassader M, et al. p53 Mediates the accelerated onset of senescence of endothelial progenitor cells in diabetes. J Biol Chem 2006;281:4339-47.

[51] Salpea KD, Humphries SE. Telomere length in atherosclerosis and diabetes. Aherosclerosis 2010;209(1):35-8.

[52] Satoh M, Ishikawa Y, Takahashi Y, Itoh T, Minami Y, Nakamura M. Association between oxidative DNA damage and telomere shortening in circulating endothelial progenitor cells obtained from metabolic syndrome patients with coronary artery disease. Atherosclerosis 2008;198:347-53.

[53] Adaikalakoteswari A, Balasubramanyam M, Ravikumar R, Deepa R, Mohan V. Association of telomere shortening with impaired glucose tolerance and diabetic macroangiopathy. Atherosclerosis 2007; 195:83-9.

[54] Olivieri F, Lorenzi M, Antonicelli R, Testa R, Sirolla C, Cardelli M, et al. Leukocyte telomere shortening in elderly Type2DM patients with previous myocardial infarction. Atherosclerosis 2009; 206:588-93.

[55] Ronti T, Lupattelli G, Mannarino E. The endocrine function of adipose tissue. Clin Endocrinol 2006;64(4):355-65.
[56] Yudkin JS, Kumari M, Humphries SE, Mohamed-Ali V. Inflammation, obesity, stress and coronary artery disease. Atherosclerosis 2000;148:209-14.

[57] Baik I, Ascherio A, Rimm EB, Giovannucci E, Spiegelman D, Stampfer MJ, et al. Adiposity and mortality in men. Am J Epidemiol 2000;152:264-71.

[58] Rexode KM, Carey VJ, Hennekens CH, Walters EE, Colditz GA, Stampfer MJ, et al. Abdominal adiposity and coronary heart disease in women. J Am Med Assoc 1998;280:1843-8.

[59] Beltowski I, Wojcicka G, Jamroz A. Leptin decreases plasma paraxonases 1 (PON 1) activity and induces oxidative stress: the possible novel mechanism for pro-atherogenic effect of chronic hyperleptinaemia. Atherosclerosis 2003;170:21-9.

[60] Jeanclos E, Schork NJ, Kyvik KO, Kimura M, Skurnick JH, Aviv A. Telomere length inversely correlates with pulse pressure and is highly familial. Hypertension 2000;36:195-200.

[61] Benetos A, Gardner JP, Zureik M, Labat C, Xiaobin L, Adamopoulos C, et al. Short telomeres are associated with increased carotid atherosclerosis in hypertensive subjects. Hypertension 2004;43:182-5.

[62] Burke A. Fitzgerald GA. Oxidative stress and smoking-induced vascular injury. Prog Cardiovasc Dis 2003;46:79-90.

[63] Ogami M, Ikura Y, Ohsawa M, Matsuo T, Kayo S, Yoshimi N, et al. Arterioscler Thromb Vasc Biol 2004;24:546-50.

[64] Chang E, Harley CB. Telomere length and replicative ageing in human vascular tissues. Proc Natl Acad Sci U S A 1995;92: $11190-4$

[65] Okuda I, Khan MY, Skurnick J, Kimura M, Aviv H, Aviv A. Telomere attrition of the human abdominal aorta: relationships with age and atherosclerosis. Atherosclerosis 2000:152:391-8.

[66] Huzen J, de Boer RA, van Veldhuisen DJ, van Gilst WH, van der Harst P. The emerging role of telomere biology in cardiovascular disease. Front Biosci (Landmark Ed) 2010 Jan 1;15:35-45.

[67] Samani NJ, Boultby R, Butler R, Thompson JR, Goodall AH. Telomere shortening in atherosclerosis. Lancet 2001;358:472-3.

[68] Brouilette S, Singh RK, Thompson JR, Goodall AH, Samani NJ. White cell telomere length and risk of premature myocardial infarction. Arterioscler Thromb Vasc Biol 2003;23:842-6.

[69] Zee RY, Michaud SE, Germer S. Ridker PM.Association of shorter mean telomere length with risk of incident myocardial infarction: a prospective, nested case-control approach. Clin Chim Acta 2009 May;403(1-2):139-41.

[70] Cawthon RM, Smith KR, O'Brien E, Sivatchenko A, Kerber RA Asociation between telomere length in blood and mortality in people aged 60 years or older. Lancet 2003;361:393-5.

[71] Brouilette SW, Moore JS, McMahon AD, Thompson JR, Ford I Shepherd J, et al. Telomere length, risk of coronary disease and statin treatment in the West of Scotland primary prevention study: a nested case-control study. Lancet 2007;369:107-14. 